\title{
Morphometric analysis of facial soft tissue thickness for sexual dimorphism: A cone beam computed tomography study
}

\author{
Manasa Anand Meundi ${ }^{1 *}$, Chaya M David ${ }^{2}$ \\ ${ }^{1}$ Professor, ${ }^{2}$ Professor and HOD, Dept. of Oral Medicine and Radiology, Dayananda Sagar College of Dental Sciences, Bengaluru, \\ Karnataka, India
}

Corresponding Author: Manasa Anand Meundi

Email: manasaanandmeundi@gmail.com

\begin{abstract}
Introduction: Facial Reconstruction is the final step attempted in forensics for the purpose of human identification wherein the facial structures are recreated over the anonymous skull to make it identifiable by the public. Population-specific facial soft tissue thickness (STT) data is essential to obtain acceptable results in facial reconstruction. Tissue thickness have wide variations owing to the influence of factors such as age, sex and race of the individuals. To this end, the aim of the present study was to provide a set of STT averages for south Indian population and to evaluate the influence of age and sex on STT averages.

Material and Methods: CBCT scans of 307 (142 males and 165 females) south Indian subjects aged 18-80yrs were selected and STT was estimated at 34 landmarks using Ondemand 3D software.

Results: STT averages were obtained. An increasing trend in STTs with advancing age was observed in both males and females. Mean STT was significantly larger in males than females at all the landmarks except at gonion. Seven variables (nasion, subnasale, pogonion, zygion, infraM2, midramus and midmandibular border) were found to be the best predictors of sex and could identify sex of $83 \%$ subjects.

Conclusion: Present study has provided mean facial soft tissue thickness values of adult south Indian population at suitable reference points. The derived discriminant function equations will be useful in sex determination of the unknown. STT along with their age and sex related variations will be valuable in forensic facial reconstructions, plastic surgeries and in anthropology.
\end{abstract}

Keywords: Sex determination, Forensic facial reconstruction, Facial soft tissue thickness, Human identification, Cone beam computed tomography, South Indian population.

\section{Introduction}

Human identification is the sine qua non of forensic odontology. Face is the first tool used in this act as this is most visible part of the human body. Under circumstances such as explosions, warfare and mass disasters however, forensic experts are challenged to establish the identity of human remains in mutilated states wherein the face is in the unrecognisable form. ${ }^{1}$ Occasionally, parts of the skeleton and skull in particular may be unearthed during archaeological $\quad$ studies. ${ }^{1} \quad$ Although Comparative identification is employed in all such situations wherein the post-mortem data of the deceased is matched with his preexisting medical and dental records, the method is of limited use in the absence / unavailability of antemortem details. Even biological identification through DNA necessitates a known profile for comparison. In all such circumstances when the investigation process reaches a blind end, forensic experts retreat to craniofacial reconstruction, an anthropological technique which aids in the identification of the deceased through recognition by the public. ${ }^{1,2}$

Craniofacial Reconstruction (CFR) is an artistic science of recreating the face of an unknown skull and give the skull a recognisable form to help in its identification during forensic investigations. ${ }^{3}$ Occasionally, CFR is employed to sculpt the faces of renowned individuals from the prehistoric times such as Egyptians and Babylonians. Since its inception in the nineteenth century, various twodimensional and three-dimensional methods have been applied in the process of reconstruction. 2D method superimposes the sketch of the predicted face on to the skull images either manually or by dedicated computer software for comparison whereas in 3D reconstruction, the entire face is moulded onto the unknown skull or its replica. The procedure employed for 3D reconstruction has varied among the practitioners. Morphoscopic/Russian method rely on the construction of the facial musculature which prerequisites sculptural expertise of certain degree; the morphometric/American method rely on the use of soft tissue depth averages has a more scientific approach whereas the Wilkinson's Manchester method amalgamates both. $^{3,4}$ Irrespective of the sequence involved in the procedure, all of the major methods advocate the construction of the soft tissues onto the skull replica under the guidance of tissue depth pegs attached to the skull surface at various points. ${ }^{5}$

Tissue depth markers beacon the anthropologists to establish a near-normal appearance of the face to the skull. The depth of the tissue markers is the averages of the facial soft tissue thickness (STT) measured at specific anatomical landmarks on the face estimated on general population. ${ }^{6} \mathrm{~A}$ variety of measurement techniques have been employed to estimate STT ranging from insertion of needles in cadavers to advanced technologies such as CT-scan and MRI. ${ }^{7}$ STT measured on cadavers are severely affected by post mortem changes and also from limited data. In living subjects, STT can be measured using lateral cephalometric radiographs, CT, MRI and ultrasound. ${ }^{8-11}$ While cephalometry yields information of the facial thickness along the midline which may also be influenced by superimpositions, ultrasound is technique sensitive wherein the pressure effects from the transducer during examination are likely to underestimate the values. Although $\mathrm{CT}$ and MRI are more precise in 
evaluating the craniofacial relationship, measurements are taken with subjects in supine position which would introduce gravity induced differences in the measurements. ${ }^{12}$ Recently developed Cone Beam Computed Tomography (CBCT) has been exclusively designed for imaging of craniofacial structures and allows the patient to be in upright position during the procedure. Furthermore, the radiation dose is much lower than for CT-scan. ${ }^{13,14}$

Reconstructed face attracts public attention and eases recognition only when it depicts the facial features exclusive of the deceased individual. Age, sex and race dependant variations in the craniofacial architecture help to add uniqueness to each individual and differentiate from one another. $^{3,15}$ Over the last century, studies have been conducted globally in various ethnic groups as racial variations have been observed in soft tissue thickness data. $^{7,10,11,16}$ It is also likely that STT may differ among genders at particular anthropological landmarks. The aims of this study were therefore to measure facial soft tissue thickness of South-Indian population; evaluate if there are sex related differences in the soft tissue thickness and also to assess the influence of age and sex on facial soft tissue thickness.

\section{Materials and Methods}

The material for this study consisted of 307 subjects (142 males and 165 females) anonymised cone beam-CT scans of South Indian individuals, aged between 18 and 80 years. Clearance was obtained from Institutional Ethical Committee and patients were subjected to scan for reasons unrelated to the current study. Patients with congenital facial deformities and those treated for head and neck trauma or pathologies, patients who have undergone or in the process of orthodontic treatment or patients with facial asymmetries any of which may compromise the facial soft tissue thickness were excluded from the study. Patients were made to stand within the Planmeca ProMax 3D Mid CBCT scanner with Frankfurt Horizontal plane (FH - plane) parallel to the floor and face in a neutral, relaxed position. Scans were made using a tube current of $8 \mathrm{~mA}$, at a tube voltage of $90 \mathrm{kV}$ and a scan time of 18 secs. With field of view (FOV) of $200 \times 170 \mathrm{~mm}$, by 360 -degree rotation of the $\mathrm{X}$-ray tube, series of images were acquired using amorphous silicon flat panel detector at a resolution of $300 \mu \mathrm{m}$. All the images were saved in the external hard disc drive in Digital Imaging and Communication in Medicine (DICOM) format. All the DICOM images were exported to ONDEMAND 3D software by CYBERMED INC, KOREA. The maxillofacial 3D images were created from the DICOM data and measurements were done using cephalometric analysis tool of the software. For controlling antero-posterior head rotation and orientation of the images, intracranial reference plane was used with F-H plane oriented horizontal in the sagittal view, mid-sagittal plane oriented vertically in the axial view and transporionic line oriented horizontally in the coronal view.

34 (12 midline and 11 bilateral) hard tissue landmarks and the corresponding soft tissue counterparts were selected for STT measurements. The landmarks were chosen as suggested by Stephan and Simpson ${ }^{5}$ who upon their extensive review of 62 studies have opined that these landmarks provide a good basis for a minimum set in STT measurements. To obtain measurements, cephalometric Analysis tool available in the software was used. The landmarks were identified on the 3D reconstructed volumetric image as per the hard tissue landmark definition. The landmark position was further located more accurately using the orthogonal sections. The corresponding soft tissue landmark was established on the soft tissue image according to the landmark definitions. The distance between the two points were automatically calculated by the program as the STT at that anatomical point.

The resulting measurement data were recorded and analysed using IBM SPSS software version 22.0. Released in 2013. Armonk, NY: IBM Corp. The analysis was done for a total of 33 landmarks. Basic descriptive statistics that include mean and standard deviation of FSTT of males and females were calculated. Student Paired t Test was used to compare the mean values of FSTT between right and left Sides in male and female subjects. Independent Student $t$ Test was used to perform gender wise comparison of FSTT and also between the genders in different age groups. Stepwise multivariate Discriminant Function analysis was performed to predict the genders by using different study variables. The level of significance [P-Value] was set at $\mathrm{P}<0.05$.

\section{Results}

The name and definitions of various landmarks at which soft tissue thicknesses were estimated in the current study have been adopted from Stephan and Simpson. ${ }^{5}$ Facial soft tissue thickness was measured at 12 midline landmarks and 11 bilateral landmarks in CBCT scans from all the 307 study subjects. However, Student Paired t-Test used to compare the mean FSTT values of the right and left sides of the face showed no significant difference at any of the eleven anatomical landmarks among both male and female subjects. Consequently, only right side values were considered for further statistical tests resulting in FSTT values at only 23 landmarks.

Averages of facial soft tissue thickness estimated in both the sexes have been presented in Table 1. STT was larger in males than females as seen in Fig. 1. Independent Student t-Test that was used to compare the mean FSTT values between males and females shows statistically significant differences between the two sexes at all the craniofacial landmarks except at zygion. Differences of $\geq$ $2 \mathrm{~mm}$ was noted between males and females at subnasale, midphiltrum, labrale superius, gonion, supracanine and infraM2 with highest sexual dimorphism observed at mid ramus region.

As shown in Table 2, Independent Student t-Test was used to compare sexual dimorphism in STT values at different age groups. At certain landmarks (nasion, midphiltrum, labrale superius and supracanine) the sexbased differences were significant at all the age groups with 
males having larger STT than females. At landmarks mid nasal, rhinion, subnasale, labrale inferius, pogonion, menton, mid supraorbital, alare curvature point and infracanine, the sex-based differences in STT were significant below 30 yrs and above 40 yrs. At supraM2, infraM2, gonion, midramus and mid mandibular border, the differences were statistically significant only beyond 40 yrs of age. At glabella and gnathion however, the differences were significant below 30 yrs and above 50 yrs.

Fig. 2 is a graphical representation depicting an increasing trend in STT with the advancing age of south Indian males. Fig. 3 represents a trend of gradual increase in STT of South Indian females at all the landmarks as the age advances. Facial soft tissues are thinner in the forehead region whereas the STT increases around the cheek and is thickest in the region of the mandible. The trend is similar in both the genders.
As shown in Tables 3 and 4, Step-wise multivariate discriminant function analysis (MDFA) of soft tissue thicknesses was estimated. Seven among the 33 variables (nasion, subnasale, pogonion, zygion, infraM2, midramus and midmandibular border) were chosen as the best landmarks to discriminate the sex. $83.1 \%$ of the subjects from the original grouped data and $100 \%$ of the subjects ( $80.5 \%$ males and $85.4 \%$ females) from cross-validated data were correctly determined. Table 5 shows the discriminant function equations for sex estimations from tissue depth values. By inserting the values at the above mentioned seven anatomical landmarks in the equations given in Table 5 , the sex of the unknown can be determined and compared with sex-specific group centroid. If the calculated value lies closer to 1.122 , then the subject is male and if the value is closer to -0.909 , then the unknown subject is a female.

Table 1: Averages of facial soft tissue thickness (mm) and their variations between two genders

\begin{tabular}{|c|c|c|c|}
\hline \multirow{2}{*}{ Landmarks } & Males & Females & \multirow{2}{*}{ P-Value } \\
\cline { 2 - 3 } & Mean \pm Std. Dev & Mean \pm Std. Dev & $<0.001^{*}$ \\
\hline glabella & $5.39 \pm 1.17$ & $4.76 \pm 1.10$ & $<0.001^{*}$ \\
\hline nasion & $7.25 \pm 1.69$ & $5.81 \pm 1.45$ & $<0.001^{*}$ \\
\hline mid nasal & $4.36 \pm 1.20$ & $3.63 \pm 0.95$ & $<0.001^{*}$ \\
\hline rhinion & $2.51 \pm 0.76$ & $2.06 \pm 0.57$ & $<0.001^{*}$ \\
\hline sub nasale & $14.11 \pm 2.32$ & $11.82 \pm 2.01$ & $<0.001^{*}$ \\
\hline mid philtrum & $12.63 \pm 2.33$ & $10.40 \pm 2.18$ & $<0.001^{*}$ \\
\hline labrale superius & $12.96 \pm 2.85$ & $10.82 \pm 2.37$ & $<0.001^{*}$ \\
\hline labrale inferius & $14.58 \pm 2.94$ & $13.02 \pm 2.80$ & $<0.001^{*}$ \\
\hline mentolabial sulcus & $11.51 \pm 2.10$ & $10.68 \pm 1.99$ & $<0.001^{*}$ \\
\hline pogonion & $12.54 \pm 3.15$ & $10.66 \pm 2.75$ & $<0.001^{*}$ \\
\hline gnathion & $8.41 \pm 2.98$ & $6.79 \pm 2.32$ & $<0.001^{*}$ \\
\hline menton & $5.76 \pm 2.14$ & $4.91 \pm 1.50$ & $0.00 *^{*}$ \\
\hline mid supraorbital & $8.39 \pm 1.78$ & $6.90 \pm 1.70$ & $<0.001^{*}$ \\
\hline mid infraorbital & $5.77 \pm 1.57$ & $5.32 \pm 1.38$ & $0.001^{*}$ \\
\hline alare curvature point & $9.67 \pm 2.15$ & $8.40 \pm 1.29$ & 0.58 \\
\hline gonion & $15.33 \pm 5.91$ & $13.30 \pm 4.68$ & $<0.001^{*}$ \\
\hline zygion & $7.54 \pm 2.29$ & $7.68 \pm 1.97$ & $<0.001^{*}$ \\
\hline supracanine & $12.70 \pm 2.31$ & $10.61 \pm 2.27$ & $0.001^{*}$ \\
\hline infracanine & $13.79 \pm 2.97$ & $12.11 \pm 2.92$ & $<0.001^{*}$ \\
\hline supraM2 & $30.66 \pm 4.95$ & $29.00 \pm 3.90$ & $0.001^{*}$ \\
\hline infraM2 & $27.06 \pm 4.88$ & $24.80 \pm 3.67$ & $0.02^{*}$ \\
\hline mid ramus & $21.65 \pm 4.51$ & $18.64 \pm 3.62$ & \\
\hline mid mandibular border & $12.76 \pm 4.84$ & $11.64 \pm 3.67$ & \\
\hline
\end{tabular}

$*$ p-value of $\leq 0.05$ is statistically significant

Table 2: Facial Soft Tissue Thickness ( $\mathrm{mm}$ ) variations in males and females in different age groups

\begin{tabular}{|c|c|c|c|c|c|c|}
\hline Landmarks & \multirow{2}{*}{ Sex } & $\mathbf{1 7 - 2 0}$ yrs & $\mathbf{2 1 - 3 0}$ yrs & $\mathbf{3 1 - 4 0}$ yrs & $\mathbf{4 1 - 5 0}$ yrs & $>\mathbf{5 0}$ yrs \\
\cline { 3 - 7 } & & Mean $\mathbf{\text { SD }}$ & Mean \pm SD & Mean \pm SD & Mean \pm SD & Mean \pm SD \\
\hline \multirow{2}{*}{ glabella } & $\mathrm{M}$ & $5.12 \pm 0.89$ & $5.16 \pm 0.82$ & $5.49 \pm 0.87$ & $5.49 \pm 1.34$ & $5.64 \pm 1.48$ \\
\cline { 2 - 7 } & $\mathrm{F}$ & $4.61 \pm 0.64^{*}$ & $4.46 \pm 0.91^{* *}$ & $4.85 \pm 1.02$ & $5.04 \pm 1.28$ & $4.83 \pm 1.30^{*}$ \\
\hline \multirow{2}{*}{ nasion } & $\mathrm{M}$ & $6.88 \pm 1.55$ & $7.17 \pm 1.13$ & $7.93 \pm 1.33$ & $7.50 \pm 1.77$ & $7.08 \pm 2.12$ \\
\cline { 2 - 7 } & $\mathrm{F}$ & $5.42 \pm 0.98^{* *}$ & $5.64 \pm 0.91^{* *}$ & $5.67 \pm 1.02^{* *}$ & $6.24 \pm 1.83^{* *}$ & $5.85 \pm 1.71^{* *}$ \\
\hline \multirow{2}{*}{ mid nasal } & $\mathrm{M}$ & $3.99 \pm 1.06$ & $4.02 \pm 0.84$ & $4.46 \pm 1.09$ & $4.72 \pm 1.24$ & $4.53 \pm 1.44$ \\
\cline { 2 - 7 } & $\mathrm{F}$ & $3.33 \pm 0.97^{*}$ & $3.38 \pm 0.76^{* *}$ & $3.65 \pm 0.97$ & $3.83 \pm 1.08^{* *}$ & $3.82 \pm 0.88^{* *}$ \\
\hline \multirow{2}{*}{ rhinion } & $\mathrm{M}$ & $2.12 \pm 0.47$ & $2.20 \pm 0.56$ & $2.48 \pm 0.65$ & $2.86 \pm 0.81$ & $2.68 \pm 0.84$ \\
\cline { 2 - 7 } & $\mathrm{F}$ & $1.93 \pm 0.40$ & $1.91 \pm 0.53^{*}$ & $2.22 \pm 0.61$ & $2.12 \pm 0.64^{* *}$ & $2.17 \pm 0.59^{* *}$ \\
\hline
\end{tabular}




\begin{tabular}{|c|c|c|c|c|c|c|}
\hline \multirow[t]{2}{*}{ sub nasale } & $\mathrm{M}$ & $14.12 \pm 1.57$ & $15.19 \pm 1.74$ & $14.95 \pm 1.63$ & $13.94 \pm 1.88$ & $13.03 \pm 3.03$ \\
\hline & $\mathrm{F}$ & $12.57 \pm 1.45^{* *}$ & $12.32 \pm 1.60^{* *}$ & $11.93 \pm 1.88$ & $11.51 \pm 2.36^{* *}$ & $11.18 \pm 2.11 * *$ \\
\hline \multirow[t]{2}{*}{ mid philtrum } & $\mathrm{M}$ & $12.76 \pm 1.31$ & $13.62 \pm 1.54$ & $13.77 \pm 1.44$ & $12.53 \pm 1.82$ & $11.43 \pm 3.18$ \\
\hline & $\mathrm{F}$ & $11.33 \pm 1.23 * *$ & $10.83 \pm 1.15^{* *}$ & $10.70 \pm 1.81 * *$ & $10.11 \pm 2.55^{* *}$ & $9.63 \pm 2.73 * *$ \\
\hline \multirow{2}{*}{ labrale superius } & $\mathrm{M}$ & $13.32 \pm 1.47$ & $13.84 \pm 2.06$ & $14.10 \pm 1.30$ & $12.66 \pm 2.73$ & $11.91 \pm 3.88$ \\
\hline & $\mathrm{F}$ & $12.01 \pm 1.57 * *$ & $11.15 \pm 1.52 * *$ & $11.80 \pm 2.08^{* *}$ & $10.11 \pm 2.62 * *$ & $10.17 \pm 2.83^{*}$ \\
\hline \multirow[t]{2}{*}{ labrale inferius } & $\mathrm{M}$ & $14.18 \pm 3.06$ & $15.25 \pm 1.98$ & $14.77 \pm 1.93$ & $14.15 \pm 2.92$ & $14.47 \pm 3.80$ \\
\hline & $\mathrm{F}$ & $13.63 \pm 1.67$ & $13.41 \pm 1.92 * *$ & $14.20 \pm 2.28$ & $12.37 \pm 3.18^{*}$ & $12.55 \pm 3.52 *$ \\
\hline \multirow[t]{2}{*}{ mentolabial sulcus } & $\mathrm{M}$ & $11.55 \pm 1.63$ & $11.15 \pm 1.80$ & $11.59 \pm 1.44$ & $11.62 \pm 2.47$ & $11.69 \pm 2.44$ \\
\hline & $\mathrm{F}$ & $10.57 \pm 2.02$ & $10.32 \pm 1.32 *$ & $11.33 \pm 1.18$ & $10.68 \pm 2.43$ & $10.86 \pm 2.19$ \\
\hline \multirow[t]{2}{*}{ pogonion } & $\mathrm{M}$ & $11.56 \pm 2.81$ & $12.05 \pm 2.53$ & $12.78 \pm 2.38$ & $13.06 \pm 3.53$ & $12.96 \pm 3.60$ \\
\hline & $\mathrm{F}$ & $10.14 \pm 2.23$ & $10.70 \pm 1.77 *$ & $12.59 \pm 2.07$ & $10.75 \pm 3.33 * *$ & $10.30 \pm 3.14 * *$ \\
\hline \multirow{2}{*}{ gnathion } & $\mathrm{M}$ & $6.71 \pm 1.95$ & $8.33 \pm 2.83$ & $8.21 \pm 2.91$ & $8.45 \pm 2.79$ & $9.33 \pm 3.39$ \\
\hline & $\mathrm{F}$ & $6.43 \pm 1.75$ & $5.97 \pm 1.72 * *$ & $7.39 \pm 2.45$ & $7.30 \pm 2.69$ & $7.04 \pm 2.53^{* * *}$ \\
\hline \multirow[t]{2}{*}{ menton } & $\mathrm{M}$ & $4.57 \pm 1.50$ & $5.25 \pm 1.35$ & $5.21 \pm 1.42$ & $6.22 \pm 2.47$ & $6.57 \pm 2.47$ \\
\hline & $\mathrm{F}$ & $4.71 \pm 1.30$ & $4.63 \pm 1.17 *$ & $5.33 \pm 1.26$ & $5.05 \pm 1.68^{*}$ & $5.02 \pm 1.74 * *$ \\
\hline \multirow[t]{2}{*}{ mid supraorbital } & $\mathrm{M}$ & $7.86 \pm 1.12$ & $8.03 \pm 1.26$ & $8.56 \pm 1.70$ & $8.98 \pm 2.00$ & $8.51 \pm 2.23$ \\
\hline & $\mathrm{F}$ & $6.72 \pm 1.33 * *$ & $6.69 \pm 1.33 * *$ & $7.58 \pm 1.30$ & $7.06 \pm 1.94 * *$ & $6.86 \pm 2.06 * *$ \\
\hline \multirow[t]{2}{*}{ mid infraorbital } & $\mathrm{M}$ & $5.29 \pm 1.00$ & $5.14 \pm 1.06$ & $5.63 \pm 2.07$ & $6.03 \pm 1.48$ & $6.38 \pm 1.79$ \\
\hline & $\mathrm{F}$ & $5.14 \pm 1.02$ & $5.33 \pm 1.37$ & $5.28 \pm 1.64$ & $5.35 \pm 1.50$ & $5.41 \pm 1.42 * *$ \\
\hline \multirow{2}{*}{$\begin{array}{c}\text { alare curvature } \\
\text { point }\end{array}$} & $\mathrm{M}$ & $9.28 \pm 1.57$ & $9.83 \pm 3.30$ & $9.04 \pm 1.63$ & $9.72 \pm 1.57$ & $9.89 \pm 1.65$ \\
\hline & $\mathrm{F}$ & $8.36 \pm 1.12 *$ & $7.89 \pm 1.24 * *$ & $8.43 \pm 1.67$ & $8.61 \pm 1.44 * *$ & $8.67 \pm 1.06^{* *}$ \\
\hline \multirow[t]{2}{*}{ gonion } & $\mathrm{M}$ & $11.96 \pm 4.21$ & $12.80 \pm 4.71$ & $14.34 \pm 4.90$ & $17.06 \pm 5.55$ & $18.02 \pm 6.49$ \\
\hline & $\mathrm{F}$ & $10.49 \pm 3.38$ & $11.98 \pm 4.57$ & $14.84 \pm 3.63$ & $14.48 \pm 4.73^{*}$ & $14.67 \pm 4.77 * *$ \\
\hline \multirow[t]{2}{*}{ zygion } & $\mathrm{M}$ & $7.56 \pm 2.33$ & $6.98 \pm 2.02$ & $7.34 \pm 1.75$ & $8.02 \pm 2.17$ & $7.71 \pm 2.68$ \\
\hline & $\mathrm{F}$ & $7.33 \pm 1.54$ & $7.86 \pm 1.89$ & $8.50 \pm 1.91$ & $7.87 \pm 2.26$ & $7.31 \pm 1.95$ \\
\hline \multirow[t]{2}{*}{ supracanine } & $\mathrm{M}$ & $12.87 \pm 2.45$ & $13.23 \pm 1.43$ & $14.27 \pm 2.21$ & $12.49 \pm 1.81$ & $11.86 \pm 2.87$ \\
\hline & $\mathrm{F}$ & $11.93 \pm 1.53$ & $11.07 \pm 1.39 * *$ & $11.28 \pm 2.14 * *$ & $10.26 \pm 2.17 * *$ & $9.50 \pm 2.80 * *$ \\
\hline \multirow[t]{2}{*}{ infracanine } & $\mathrm{M}$ & $13.55 \pm 2.30$ & $13.77 \pm 2.75$ & $14.40 \pm 2.83$ & $13.78 \pm 3.19$ & $13.73 \pm 3.39$ \\
\hline & $\mathrm{F}$ & $12.18 \pm 2.18 *$ & $12.15 \pm 2.59^{*}$ & $13.02 \pm 3.24$ & $12.17 \pm 3.35^{*}$ & $11.71 \pm 3.11 * *$ \\
\hline \multirow[t]{2}{*}{ supraM2 } & $\mathrm{M}$ & $28.55 \pm 3.67$ & $30.11 \pm 4.18$ & $29.11 \pm 5.24$ & $31.92 \pm 5.63$ & $31.85 \pm 5.17$ \\
\hline & $\mathrm{F}$ & $28.04 \pm 2.57$ & $28.83 \pm 4.34$ & $31.45 \pm 2.65$ & $29.36 \pm 4.27 *$ & $28.64 \pm 3.97 * *$ \\
\hline \multirow[t]{2}{*}{ infraM2 } & $\mathrm{M}$ & $24.26 \pm 4.37$ & $26.09 \pm 4.19$ & $25.64 \pm 4.71$ & $28.23 \pm 3.71$ & $28.96 \pm 5.68$ \\
\hline & $\mathrm{F}$ & $23.20 \pm 2.71$ & $25.20 \pm 3.48$ & $27.75 \pm 3.04$ & $25.12 \pm 3.93 * *$ & $24.25 \pm 3.85^{* *}$ \\
\hline \multirow[t]{2}{*}{ mid ramus } & $\mathrm{M}$ & $18.88 \pm 3.66$ & $19.91 \pm 4.05$ & $20.70 \pm 3.47$ & $23.28 \pm 4.06$ & $23.46 \pm 4.71$ \\
\hline & $\mathrm{F}$ & $17.53 \pm 2.81$ & $18.23 \pm 3.27$ & $21.26 \pm 2.89$ & $19.46 \pm 3.92 * *$ & $18.16 \pm 3.86^{* *}$ \\
\hline \multirow{2}{*}{$\begin{array}{l}\text { mid mandibular } \\
\text { border }\end{array}$} & $\mathrm{M}$ & $9.55 \pm 3.95$ & $10.10 \pm 3.44$ & $11.52 \pm 4.48$ & $14.44 \pm 3.85$ & $15.61 \pm 4.94$ \\
\hline & $\mathrm{F}$ & $8.98 \pm 2.79$ & $10.62 \pm 3.57$ & $13.92 \pm 3.03$ & $12.27 \pm 3.81^{*}$ & $12.94 \pm 3.16^{* *}$ \\
\hline
\end{tabular}

$* \mathrm{p}: \leq 0.05 ; * * \mathrm{p}: \leq 0.01$ - statistically significant

Table 3: Classification functions of Step-wise Multivariate Discriminant Function Analysis for sex discrimination

\begin{tabular}{|c|c|c|c|c|c|c|c|}
\hline Variables chosen & Tolerance & F to Remove & Wilks' Lambda & SCDFC & CDFC & Males & Females \\
\hline subnasale & 0.839 & 25.870 & 0.544 & 0.470 & 0.230 & 2.702 & 2.235 \\
\hline nasion & 0.722 & 24.416 & 0.542 & 0.494 & 0.345 & 1.955 & 1.254 \\
\hline zygion & 0.397 & 58.413 & 0.609 & -0.972 & -0.457 & -2.035 & -1.108 \\
\hline mid ramus & 0.248 & 26.379 & 0.546 & 0.873 & 0.217 & 1.366 & 0.925 \\
\hline mid mandibular border & 0.250 & 13.339 & 0.520 & -0.634 & -0.146 & -2.125 & -1.829 \\
\hline infraM2 & 0.294 & 6.632 & 0.506 & 0.417 & 0.098 & 2.376 & 2.177 \\
\hline pogonion & 0.725 & 4.839 & 0.503 & 0.228 & 0.080 & 0.677 & 0.514 \\
\hline Constant & & & & & -7.827 & -57.514 & -41.404 \\
\hline
\end{tabular}

SCDFC: Standardized Canonical Discriminant Function Coefficients; CDFC: Canonical Discriminant Function Coefficients; Male group centroid $=1.122 ;$ Female Group Centroid $=-0.909$ 
Table 4: Sex determination table of cross validated results from Step-wise Multivariate Discriminant Function Analysis

\begin{tabular}{|c|c|c|c|c|c|}
\hline \multirow[t]{2}{*}{ Cross Validated } & \multirow[t]{2}{*}{ Category } & \multirow[t]{2}{*}{ Gender } & \multirow{2}{*}{\begin{tabular}{|c|} 
Predicted Group Membership \\
Males
\end{tabular}} & \multirow[b]{2}{*}{ Females } & \multirow[t]{2}{*}{ Total } \\
\hline & & & & & \\
\hline \multirow[t]{4}{*}{ Prediction } & \multirow[t]{2}{*}{$\mathrm{n}$} & Males & 107 & 26 & 133 \\
\hline & & Females & 22 & 129 & 151 \\
\hline & \multirow[t]{2}{*}{$\%$} & Males & 80.5 & 19.5 & 100 \\
\hline & & Females & 14.6 & 85.4 & 100 \\
\hline
\end{tabular}

Table 5: Canonical discriminant function equations for sex estimation

\begin{tabular}{|l|l|}
\hline \multicolumn{1}{|c|}{ Condition } & Equation \\
\hline If sex is Unknown & $-7.827+0.230(\mathrm{sn})+0.345(\mathrm{n})-0.457(\mathrm{zy})+0.217(\mathrm{mr})-0.146(\mathrm{mmb})+0.098(\mathrm{iM} 2)+0.080(\mathrm{pg})$ \\
\hline If sex is Male & $-57.514+2.702(\mathrm{sn})+1.955(\mathrm{n})-2.035(\mathrm{zy})+1.366(\mathrm{mr})-2.125(\mathrm{mmb})+2.376(\mathrm{iM} 2)+0.677(\mathrm{pg})$ \\
\hline If sex is Female & $-41.404+2.235(\mathrm{sn})+1.254(\mathrm{n})-1.108(\mathrm{zy})+0.925(\mathrm{mr})-1.829(\mathrm{mmb})+2.177(\mathrm{iM} 2)+0.514(\mathrm{pg})$ \\
\hline
\end{tabular}

sn: subnasale; n: nasion; zy: zygion; mr: mid ramus; mmb: mid mandibular border; iM2: infraM2; pg: pogonion

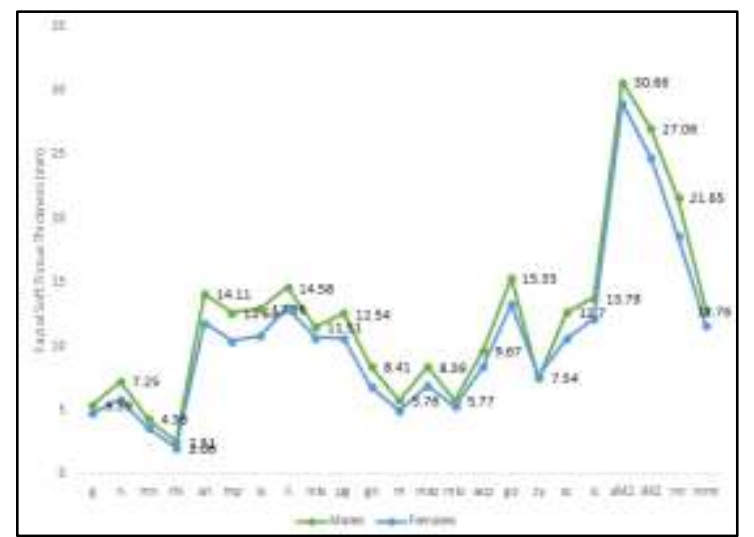

Fig. 1: Facial Soft Tissue Thickness variations in males and females

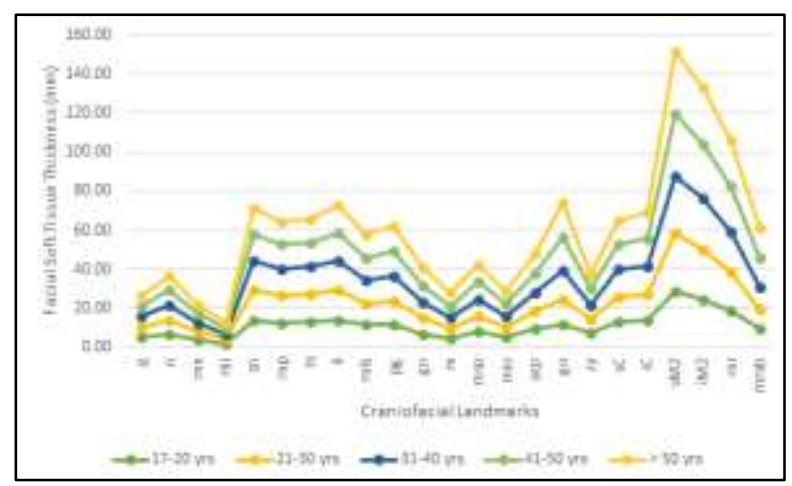

Fig. 2: Facial Soft Tissue Thickness variations with advancing age in males

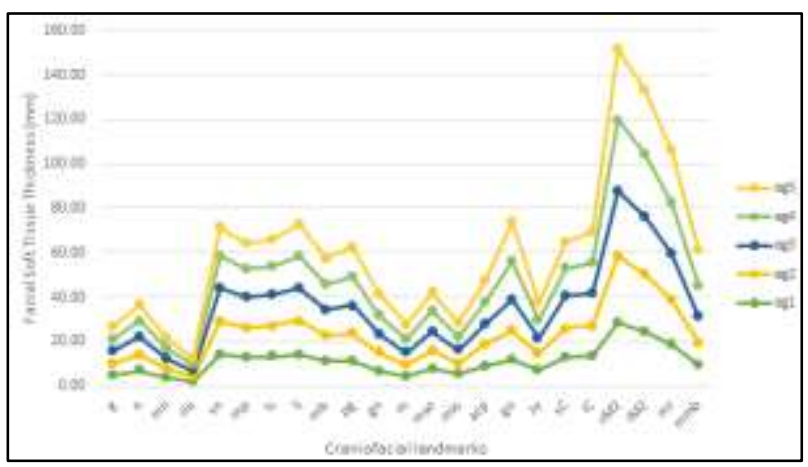

Fig. 3: Facial Soft Tissue Thickness variations with advancing age in females 


\section{Discussion}

Establishing the identity of skeletonised human remains is a challenging task for both forensic investigators and anthropologists. ${ }^{1}$ Distinguishing the gender will reduce the search population for identification by half thus simplifying further procedures. Sex determination is $98 \%$ accurate when the whole skeleton is available. Skull possesses $90 \%$ accuracy and has the second highest sex discriminant potential, first being the pelvis. ${ }^{17}$ The present study evaluated whether the facial soft tissues overlying the skull shows significant gender-based differences in its thickness analogous to the skull.

Facial reconstruction in forensics is a scientific art of recreating the face on the anonymous skull to facilitate its identification. The Technique relies heavily on the average facial soft tissue thickness measurements at pre-determined anatomical landmarks to improve the likeness of the rebuilt face. Although various studies across the globe have measured on a range of $10^{18}$ to $52^{11}$ landmarks, measurements in the present study Was done only at 34 landmarks as per Stephan and Simpson who from the systematic review suggested that measuring at 34 landmark sites would be sufficient enough for reconstruction of the face to a recognisable degree. ${ }^{5}$ The results of the current study provide a set of average STT measurements measured at 34 anatomical landmarks for South Indian males and females.

Since the $18^{\text {th }}$ century, STT has been measured by using invasive techniques such as needle puncture method to noninvasive ones like radiographs. The present study used cone beam computed tomography; a technique intended specifically for maxillofacial imaging. Being a three dimensional imaging technique, it provides a good representation of soft tissues and facilitates a comparative assessment of both hard and soft tissues simultaneously. ${ }^{19}$ Since the machine is reasonably priced when compared to $\mathrm{CT}$, smaller in size requiring smaller foot size and hence the space, and images at par with CT imaging, ${ }^{19}$ it is more likely to be easily available in forensic caseworks for postmortem scanning and virtopsies of body parts.

The present study provides average STT measurements of South Indian population. Observations of the values indicate that Facial soft tissue thickness values are lower in the upper facial region when compared to other regions of the face possibly because the soft tissues of the region are tightly adherent to the underlying skull. $^{20}$ The values are comparable to those of Kotrashetti and Mallapur ${ }^{8}$ done on South Indian population at all the common landmarks except at gonion where the values differ more than $2 \mathrm{~mm}$. The authors have measured tissue thickness at gonion using antero-posterior radiograph which is inherent with superimpositions. Additionally, it being a two-dimensional radiograph, visualisation of the landmark in all the three planes is restricted thus compromising on the accuracy of landmark identification. CBCT overcomes such limitations wherein the structures can be better visualised on 3D reconstructed images which enhance identification of craniometric landmarks with precision. Being an isotropic imaging modality, CBCT is devoid of magnification which ensures that the measurements made are accurate and reliable. As observed in Northwest Indians ${ }^{10}$ and Chinese subjects, ${ }^{21}$ STT of South Indian population in the current study showed an increasing trend in the values at upper and middle third of the face and decreasing trend at the lower facial points along the midline.

Insignificant differences noted in the STT values between the right and left sides of the face support no facial asymmetry. The results are in concordance with that observed in Spanish population ${ }^{22}$ and German adults. ${ }^{9}$ Even Sahni et al. did not find any statistically significant difference between right and left STT among northwest Indian adult males and females. ${ }^{10}$

Measured data was analysed on the basis of age and sex. STT was compared at five progressive age groups within the same sex and between sexes. Variations in STT with advancing age was negligibly small within the same gender. However, the values vary significantly between the genders. In the regions around the upper lip (midphiltrum, labrale superius, supracanine), the differences were significant at all age groups whereas at areas around the cheek and the mandible (supraM2, infraM2, gonion, mid ramus and mid mandibular border), the differences were significant only beyond $40 \mathrm{yrs}$. Since the age and sex of the skull will be assessed prior to the start of the reconstruction process, these observations may be utilised for improved results. Wilkinson observed no definite relation in the STT values and the advancing age although there is a trend of decrease in STT around the mouth and cheek areas while STT being increased at the chin as age advances. ${ }^{15}$ Similar pattern is observed in the current study which is noticeable evidently in females than in males.

The results of the present study demonstrated higher STT in males than females at all the facial areas except at zygion. Craniometrically, male skulls are larger and more robust than female skulls. In addition, due to the differences in the hormonal influences, males have stronger and larger musculature as compared to females. ${ }^{23}$ However, the landmark zygion which is the point on the lateral most curvature of the zygomatic arch lies in the cheek region where females possess thicker soft tissues than males due to presence of subcutaneous fat in abundance. ${ }^{10}$ Several studies have found that males have thicker soft tissues at majority of the facial regions than females which is in concordance with the results of the current study. ${ }^{8,10,16,24}$

Multivariate Discriminant Function Analysis showed higher predictive value $(80.5 \%$ in males and $85.4 \%$ in females) in determination of sex accurately. Kaur et al. in their study on STT of northwest Indians observed similar results wherein the STT was analysed using CT and MRI. ${ }^{24}$ This emphasise that sexual dimorphism play a vital role and hence should be taken into account during facial reconstruction. In addition, the discriminant function equation that has been derived assist in the estimation of gender whenever necessary.

Apart from age and sex, multiple factors including race, ethnicity and nutritional status influence the STT. Studies 
have shown that soft tissue thickness measurements increases with increased BMI and these changes are common to both genders alike. ${ }^{25,26}$ Nevertheless, since the present study utilised the pre-existing CBCT scans which were done for purposes not intended for this study, the data of height and weight of not all the subjects were available for calculating BMI. Remaining small subject cohort with average BMI showed no noteworthy relationship between the BMI and STT.

Variation in the STT values when compared to other population may be attributed to racial and regional diversities apart from the impact of local factors such as nutrition. As future work, the authors of the current research intend to evaluate facial soft tissue thickness among other racial groups and also estimate BMI to understand the interplay of age, sex and BMI of the individual in forming facial soft tissue thickness. Apart from this, estimating STT in younger adults is important which will be beneficial during orthognathic surgeries apart from finding its application in forensic facial reconstruction.

\section{Conclusion}

The present study has provided a set of average facial soft tissue thickness for adult South Indian population using CBCT; explored facial soft tissue thickness of male and female at different age groups and evaluated the statistical significance of STT measurements between the genders at different age groups. Results of the analysis show sexual dimorphism with a significantly higher STT in males of all ages than in females. In both men and women, there is an increasing trend in STT values noted at all the points with advancing age. Facial soft tissue thicknesses were lower in the regions of upper face and chin while its larger in the regions around the mandible. Present study can provide valuable information for facial reconstruction of south Indian population with insights on influence of age and sex on facial soft tissue thickness.

\section{Acknowledgements}

The authors would like to express their gratitude to the Principals and Heads of the Department of Oral Medicine and Radiology of Manipal College of Dental Sciences, Mangalore, AJ Shetty Institute of Dental Sciences, Mangalore, AB Shetty Institute of Dental Sciences, Mangalore, PMS college of Dental Sciences and Research, Thiruvananthapuram and MNR Dental College and Hospital, Hyderabad, for sharing their archival data for the current study. Authors are also thankful to Cybermed Inc. (Seoul, Korea) for providing access to OnDemand32 ${ }^{\text {TM }}$ software for this research work.

\section{Conflicts of interest: None.}

\section{Financial Support: None.}

\section{References}

1. Pretty I a, Sweet D. A look at forensic dentistry--Part 1: The role of teeth in the determination of human identity. Br Dent $J$
2001;190(7):359-66.

2. Tim T, Sue B. Forensic Human Identification- An Introduction. In: Tim T, Sue B, editors. Forensic human identification. New York, NY: CRC Press, Boca Raton, London; 2007:231-55.

3. Wilkinson C. Facial reconstruction - anatomical art or artistic anatomy? $J$ Anat 2010;216(2):235-50.

4. Stephan CN. Facial Approximationation and Craniofacial superimposition. Smith C, editor. Encyclopedia of Global Archeology. Springer Science + Business Media New York; 2014:2721-9.

5. Stephan CN, Simpson EK. Facial soft tissue depths in craniofacial identification (part I): An analytical review of the published adult data. J Forensic Sci 2008;53(6):1257-72.

6. Ullrich H, Stephan CN. a Nthropologie Mikhail Mikhaylovich Gerasimov' S Authentic Approach To Plastic Facial. 2016;(2014):97-107.

7. Domaracki M, Stephan CN. Facial soft tissue thicknesses in Australian adult cadavers. J Forensic Sci 2006;51(1):5-10.

8. Kotrashetti VS, Mallapur MDD. Radiographic assessment of facial soft tissue thickness in South Indian population - An anthropologic study. J Forensic Leg Med 2016;39:161-8.

9. Thiemann N, Keil V, Roy U. In vivo facial soft tissue depths of a modern adult population from Germany. Int J Legal Med 2017;131(5):1455-88.

10. Sahni D, Sanjeev, Singh G, Jit I, Singh P. Facial soft tissue thickness in northwest Indian adults. Forensic Sci Int 2008;176(2-3):137-46.

11. De Greef S, Claes P, Vandermeulen D, Mollemans W, Suetens $\mathrm{P}$, Willems $\mathrm{G}$ et al. Large-scale in-vivo Caucasian facial soft tissue thickness database for craniofacial reconstruction. Forensic Sci Int 2006;159(1).

12. Bamforth JS. Anthropometry of Soft Facial Tissues. In: Preedy, editor. Handbook of Anthropometry. New York, NY: Springer New York 2012:575-91.

13. Lindfors N, Lund H, Johansson H, Ekestubbe A. Influence of patient position and other inherent factors on image quality in two different cone beam computed tomography (CBCT) devices. Eur J Radiol Open 2017;4:132-7.

14. Al-Okshi A, Lindh C, Salé H, Gunnarsson M, Rohlin M. Effective dose of cone beam CT (CBCT) of the facial skeleton: A systematic review. Br J Radiol 2015;88(1045).

15. Wilkinson CM. Forensic Facial Reconstruction. UK: cambridge University Press; 2004.

16. Sandamini H, Jayawardena A, Batuwitage L, Rajapakse R. Facial soft tissue thickness trends for selected age groups of Sri Lankan adult population. Forensic Sci Int 2018;293:102.e1102.e11.

17. Uysal S, Gokharman D, Kacar M, Tuncbilek I, Kosa U. Estimation of sex by 3D CT measurements of the foramen magnum. J Forensic Sci 2005;50(6):1310-4.

18. Hamid S, Abuaffan AH. Facial soft tissue thickness in a sample of Sudanese adults with different occlusions. Forensic Sci Int 2016;266:209-14.

19. Scarfe WC, Li Z, Aboelmaaty W, Scott SA, Farman AG. Maxillofacial cone beam computed tomography: Essence, elements and steps to interpretation. Aust Dent J 2012;57:4660 .

20. Utsuno H, Kageyama T, Deguchi T, Yoshino M, Miyazawa H, Inoue $\mathrm{K}$ et al. Facial soft tissue thickness in Japanese female children. Forensic Sci Int 2005;152(2-3):101-7.

21. Chen F, Chen Y, Yu Y, Qiang Y, Liu M, Fulton D, et al. Age and sex related measurement of craniofacial soft tissue thickness and nasal profile in the Chinese population. Forensic Sci Int 2011;212(1-3):272.e1-272.e6.

22. Muñoz SRT, Cantín M, Rojas FJP, Galdames IS. Evaluation of facial asymmetry using soft-tissue thickness for forensic purposes. Int J Morphol 2011;29(3):1033-9. 
23. Simpson E, Henneberg M. Variation in soft-tissue thicknesses on the human face and their relation to craniometric dimensions. Am J Phys Anthropol 2002;118(2):121-33.

24. Kaur K, Sehrawat JS, Bahadur R. Sex dependent variations in craniofacial soft-tissue thicknesses estimated from MRI and CT scans: A pilot study based on Northwest Indian subjects. Int J Diagnostic Imaging 2017;4(2):47.

25. Dong Y, Huang L, Feng Z, Bai S, Wu G, Zhao Y et al. Influence of sex and body mass index on facial soft tissue thickness measurements of the northern Chinese adult population. Forensic Sci Int 2012;222(1-3):396.

26. de Greef S, Vandermeulen D, Claes P, Suetens P, Willems G, Willems PSÆG. The influence of sex, age and body mass index on facial soft tissue depths. Forensic Sci Med Pathol 2009;5(2):60-5.

How to cite this article: Meundi MA, David CM. Morphometric analysis of facial soft tissue thickness for sexual dimorphism: A cone beam computed tomography study. Int J Forensic Med Toxicol Sci 2019;4(2):60-2. 